\title{
Stroop can occur without Garner interference: Strategic and mandatory influences in multidimensional stimuli
}

\author{
CEES VAN LEEUWEN and LIESBETH BAKKER \\ University of Amsterdam, Amsterdam, The Netherlands
}

\begin{abstract}
Stroop and Garner interference were studied in two experiments involving stimuli with several irrelevant features. Using these stimuli, which were more complex than those usually used in perceptual interference studies, a new phenomenon occurred: Stroop effects without a corresponding Garner interference were obtained in four out of six nontarget conditions, two with local and two with global targets. The effects with local targets were anomalous: on one dimension, incongruous Stroop stimuli were better than congruous ones, while on the other dimension, effects were restricted to a condition in which all nontargets were congruous. With global targets, more consistent cases of Stroop-without-Garner effects were obtained. All Stroop effects were replicated in Experiment 2, in which presentation time was varied. The effects showed a strong dependency on presentation time, in such a way as to suggest a dynamic growth of the percept. The results were interpreted in terms of an interaction between automatic and strategic components of perceptual processes, in agreement with a recently introduced perceptual-organization model, which yields a new interpretation of priming and interference phenomena.
\end{abstract}

Studies of attentional selection have proven useful for understanding perceptual organization (Holender, 1992; MacLeod, 1991; Pomerantz \& Pristach, 1989). Stimuli typically consist of two dimensions - one for the target and one for the irrelevant information. Incongruity or variation on the irrelevant stimulus dimension can lead to reduced performance on the task. Such effects indicate that at some stage, nontarget information is processed together with the target information.

Incongruity was originally investigated by Stroop (1935), who showed that naming the ink color of a word was delayed if the color was different from the word named (e.g., if the word red were printed in green ink). Stroop interference, defined more generally as the drop in performance resulting from incongruity between the relevant and irrelevant dimensions, has been reported in a wide variety of conditions (MacLeod, 1991).

The irrelevant stimulus variation effect was named after Garner (1970), and is at least as pervasive as the incongruity effect. Garner (1988) experimented with stimuli that included the dimensions of letter and color, using a speeded classification task. The colors were green or red and the letters were $C$ or $O$. The content of the irrelevant dimension was held constant in one condition, and in another condition it was varied. Irrelevant variation was shown to interfere with target identification.

The authors wish to thank Silvia Russel and Menno Hogeboom for assistance in performing the experiments. Requests for reprints should be sent to C. van Leeuwen, University of Amsterdam, Department of Psychonomics, Roetersstraat 15, 1018 WB Amsterdam, the Netherlands (e-mail: ceesvl@uvapsy.psy.uva.nl).
Congruity and variation effects can be studied jointlyfor instance, by using the pairs of parentheses shown in Figure 1. One member of the pair being the target, both members could take one of two values on the "orientation" dimension. As a result, the nontarget is congruous with the target in some conditions and incongruent with it in others. In addition, in some conditions, the nontarget may be held constant, whereas in others, it could be varied from trial to trial. A variety of such experiments was performed by Pomerantz and his colleagues (e.g., Pomerantz \& Pristach, 1989; see also Pomerantz \& Garner, 1973). Pomerantz, Pristach, and Carson (1989) observed that in some conditions, both Stroop and Garner interference were obtained, while in others, only Garner interference was obtained, and in still others, neither was obtained.

Accordingly, three types of cross-dimensional information integration were distinguished: Separable dimensions are characterized by the absence of both Stroop and Garner interference (e.g., the compound letters when presented foveally [Pomerantz \& Sager, 1975]); integral dimensions have Garner-without-Stroop interference (e.g., in all the pairs of parentheses in Figure 1, which the authors referred to as "normally oriented parentheses"); and configural dimensions show both Garner and Stroop interference (e.g., the compound-letter stimuli used by Navon [1977], when presented parafoveally).

Pomerantz et al. (1989) interpreted these types of integration as follows (see Figure 2): Separable dimensions D1 and D2 are processed by separate channels along the whole trajectory (via sensory detectors, intervening modules or stages, and response production stages); neither Stroop nor Garner interference results from this situation. 
With integral dimensions, an emergent feature (a relation among parts or other features - e.g., the symmetrical or parallel orientation of line segments in the pairs of parentheses) dominates perception. Attending an emergent feature may be preferred, because, for instance, it is more efficient than processing D1 or D2 separately. When D1 is being responded to, variation on D2 increases the process load, leading to Garner interference. However, the relevant channel (EF) does not contain incongruous information, and Stroop interference cannot therefore arise.

Configural dimensions, in which there is information leakage between channels, constitute a second way in which Garner interference is handled in the model. This could occur in any of the stages. The result is equivalent to the failure of selective attention-that is, information leaking from the irrelevant channel causes Garner interference. Stroop interference arises also in this situation, when the information leaking in calls for a response that is opposite to that required by the information in the relevant channel.

In this feedforward approach, information processing in an early stage is unaffected by whatever occurs in later stages. Melara and Marks (1990) have shown, however, that for processing linguistic information, crosstalk can occur downstream: Semantic information caused Garner interference in the classification of utterances on a loudness dimension. It therefore seems that an interactive, rather than a feedforward, style of modeling is needed to explain interference phenomena.

Distinguishing stages in terms of whether they are semantics-free or semantically informed seems less straightforward for pictorial information (e.g., Turvey, 1973). This complicates the effort to test assumptions similar to those of Melara and Marks (1990), in terms of pictorial information. A consequence of Pomerantz et al.'s (1989) approach that is open to experimental testing, however, is the impossibility of Stroop interference without Garner interference. Until the present study, this prediction had been confirmed in experimental situations.

This absence-of-Stroop-without-Garner effect could be ascribed to the use of overly simple stimuli. Our experiments, therefore, studied the effect of multiplestimulus dimensions, in which interactive processing might attain a more predominant role. Network ecology

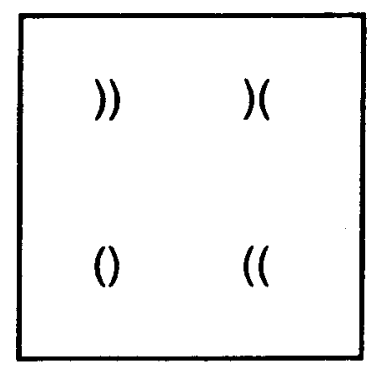

Figure 1. The normally oriented parentheses used by Pomerantz and Garner (1973).

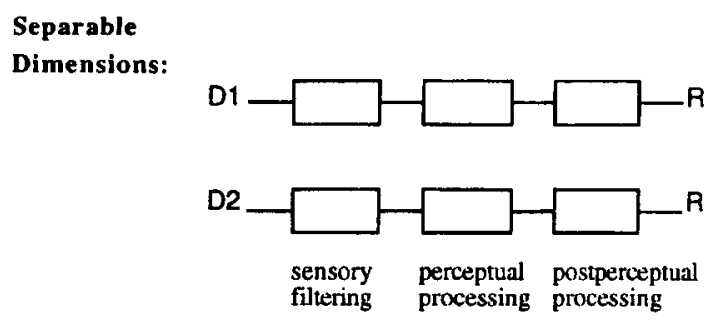

Integral

Dimensions:

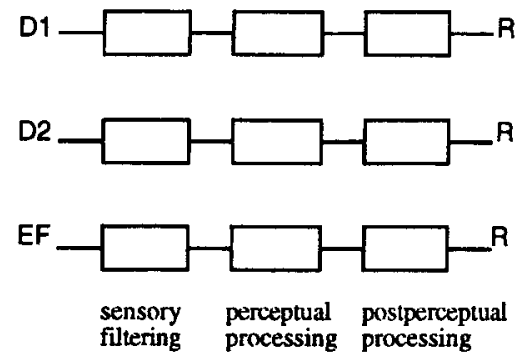

Configural

Dimensions:

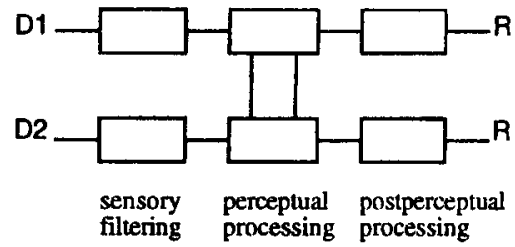

Figure 2. Three possible relations among dimensions, according to Pomerantz et al. (1989): Separable dimensions (top) — stimulus dimensions D1 and D2 are processed by separate channels leading to a response (R); integral dimensions (middle)-Garner interference occurs through emergent features (EF); and configural dimensions (bottom) --Stroop and Garner interference occur through crosstalk.

theory (NET; van Leeuwen, in press) assumes that Stroop and Garner effects occur through the interaction of automatic and strategic components. Whereas feedforward models tend to decompose the process horizontally, placing an automatic component temporally before the strategic one, decomposition in NET is vertical (see Pattee's [1973] concept of hierarchical decomposition), with automatic processes occurring as interactions between small-scale components of the system, and strategic ones occurring as interactions between large-scale components. It may therefore seem that assumptions similar to those of Treisman and Gelade (1980) are made, whereby incoming information on different dimensions is represented initially in different areas or subareas of the brain. Location, color, and shape, as well as different aspects of shape, are therefore initially separate. Processing within these areas is automatic, resulting from microscale interactions. Information can become integrated across dimensions through a process of attentionally controlled dynamic binding.

The NET approach, however, departs from Treisman and Gelade's (1980) views on how the role of attention 
is specified. Whereas in Treisman's approach, attention is understood in terms of capacity limitations on the binding process, in NET, attention is an aspecific, tuning parameter of an otherwise automatic informationintegration process. The latter is specified in term of synchronization of oscillatory activity (von der Malsburg \& Schneider, 1986). Synchronization will start between neighboring units, but may rapidly go beyond that, as two synchronized units, may, in turn, synchronize a third one, and so on. Higher-order patterns of information can be obtained, through automatic binding of information from several different features. This formation of higherorder patterns of information is called hologenesis (Pomerantz \& Pristach, 1989, used the notion of "perceptual glue"). With this concept, it is possible to understand not only how, during early perception, components join together to form a recognizable pattern (Biederman, 1987), but also how, approximately $100 \mathrm{msec}$ later, initially unrelated figures join into an integrated representation. Thus, for instance, a global gestalt is obtained out of an initially mosaic interpretation (Sekuler \& Palmer, 1992).

The assumption of hologenesis leads to an alternative approach to Stroop and Garner interference. Whereas NET shares with Pomerantz et al.'s (1989) model the overall assumption that these effects are a consequence of cross-dimensional integration, it emphasizes that the degree of information integration develops as a function of time. Hologenesis makes it possible that within a single trial, narrow-context information can be integrated earlier than broad-context information. Stroop interference is bound to a narrow context, as it develops within the time frame of that trial. Moreover, for Stroop interference to occur, it is essential that the incongruous information is (approximately) simultaneous with the target (Flowers, 1990). By contrast, Garner effects build up between trials, and Garner interference therefore operates in a broader time frame and is thus understood as an effect of broad context.

Because in hologenesis narrow-context information is integrated earlier than broad-context information, Stroop interference can arise earlier than Garner interference within a trial. In other words, within a trial, the time frames of Stroop and Garner interference project at different moments onto the hologenetic process. This is not to imply, however, that Stroop interference is due to preattentional perception alone; the process is attentionally supervised from the initial moments of time.

NET does not preclude semantic influence during early perception-hologenesis cuts through the usual dichotomy of semantically poor and semantically informed perception. It does distinguish, however, between narrow (e.g., lexical) and broad (e.g., sentence-level) semantic contexts. The general hologenetic principle that narrow context is integrated earlier than broad context allows an explanation of such phenomena as early neglect of sentence context in lexical priming (as observed in the well-known studies of Swinney [1979]), without the need to distinguish modules or stages.
NET does not preclude Stroop interference in the surrounding context (Eriksen \& Eriksen, 1974). Early narrow-context information from the scene will give rise to Stroop interference; later within the trial, broadercontext information from the earlier episode will give rise to Garner interference, but of course this late stage of processing can also give rise to Stroop interference from more spatially distant contexts.

The attentional control on the hologenetic process is executed in the model by setting a maximal coherence length. Coherence length (Geissler, 1991; Lebedev, 1990 ) is understood as the maximal duration of a process before it is disrupted. It was recently interpreted in terms of chaotic oscillations revolting against the hologenetic binding forces (van Leeuwen \& Steijvers, 1994); the strength of the binding forces relative to the disruptive force of chaos determines the coherence length. In accordance with the vertical decomposition of the model, coherence length can only be adjusted for a functional group of neural units as a whole. Suppose the hologenetic process has just accomplished grouping of all units representing a single figure. Disruption will cause further information integration to be cut off, before information from beyond the figure (e.g., from the episode prior to the presentation of the figure) could be integrated. With a longer coherence period, the broader context would be integrated with the figure. Thus, attention modulates perception on the dimension of nonintegration or integration, a nonintegrative strategy (i.e., a short coherence period) delimiting the hologenesis to a small spatiotemporal window, and an integrative strategy (i.e., a long coherence period) allowing a wider spatiotemporal window. This has its consequences for interference, in that a nonintegrative strategy will suppress interference, whereas an integrative strategy will permit it.

Coherence length may depend on expectancies regarding task complexity and variation (van Leeuwen, Hogeboom, \& Bakker, 1995; van Leeuwen, Weitenberg, \& Smit, 1995), type of task (Stins \& van Leeuwen, 1993), instruction (van Leeuwen, Hogeboom, \& Rouw, 1995), and individual preferences (Hogeboom \& van Leeuwen, 1995), and therefore accounts for the distinction between analytic and holistic processing.

An integrative strategy will enhance context sensitivity during all stages of the hologenetic process affected by the strategy. This will express itself in more priming or biasing effects on the interpretation of a figure either from the surrounding context (van Leeuwen, Weitenberg, \& Smit, 1995), from the preceding context (Stins \& van Leeuwen, 1993), from episodic information (van Leeuwen, Hogeboom, \& Rouw, 1995), or from semantic information (de Groot, 1984, 1985).

During the hologenetic process, the strategy may either stay the same or shift from an integrative to a nonintegrative one (or vice versa). This assumption leads to four possible combinations of hologenesis and strategy, the result of distinguishing between early and late information integration during hologenesis (according to whether more narrow-context or broad-context infor- 
mation is processed), and between whether the strategy is integrative or nonintegrative (see Figure 3 ). These distinctions are merely ideal types, as NET regards both hologenesis and coherence length as continuous. The four resulting combinations differentially affect Stroop and Garner interference: when strategy is nonintegrative both early and late during hologenesis, separable dimensions are obtained, characterized by an absence of Stroop and Garner interference; with an integrative strategy during these two time intervals, there will be interaction between dimensions during both intervals, resulting in configural dimensions, in which both Stroop interference (from early hologenesis) and Garner interference (from later hologenesis) are obtained. The fact that for configural dimensions, as with the compound Navon stimuli, predominance of global attention is predicted throughout was confirmed by Paquet (1994).

If more complex figures are used, a strategy change during hologenesis becomes more likely. A nonintegrative strategy early in hologenesis in combination with a later integrative strategy leads to Garner-without-Stroop interference, characteristic of integral dimensions. This order of strategies recapitulates hologenesis on the strategic level, and might therefore be the preferred way to perform a wide range of tasks that involve the recognition of nested hierarchical structures in a percept. Van Leeuwen, Buffart, and van der Vegt (1988) have shown that serial patterns were recalled by initially taking into account only the stimulus that was actually present and by later also using prior information, with gradually widening scope. This combination of strategies may be optimal for tasks requiring an initially context-independent view of independent elements of the scene, in combination with an overall view; it may, for instance, initially provide a maximum number of salient retrieval cues for the scene and exclude irrelevant higher-order regularities (Elman, 1993).

Finally, situations are possible in which early integration of information is followed by nonintegrative further processing. If, for instance, the stimulus is a good form (i.e., a dense or regular shape), this could facilitate a first orientation, so it may be useful to start integratively (LaGasse, 1993), while in order to select the target from many alternatives within the scene, a subsequent shift to a nonintegrative strategy may be advantageous - it may, for instance, allow a context-free view (a "popout") of the relevant local detail to occur. Such a situation is one in which Stroop, but not Garner, interference will be expected because, according to NET, the former interference arises earlier than the latter, but interference requires an integrative strategy.

This last alternative distinguishes between the predictions of Pomerantz et al.'s (1989) model and those of NET. We will use the term "glued dimensions" when describing this situation, to contrast it with the previous situations. The shift in strategy that is required to obtain Stroop-without-Garner interference-from an integrative to a nonintegrative one-runs counter to hologenesis, and it is not, therefore, likely that this combination

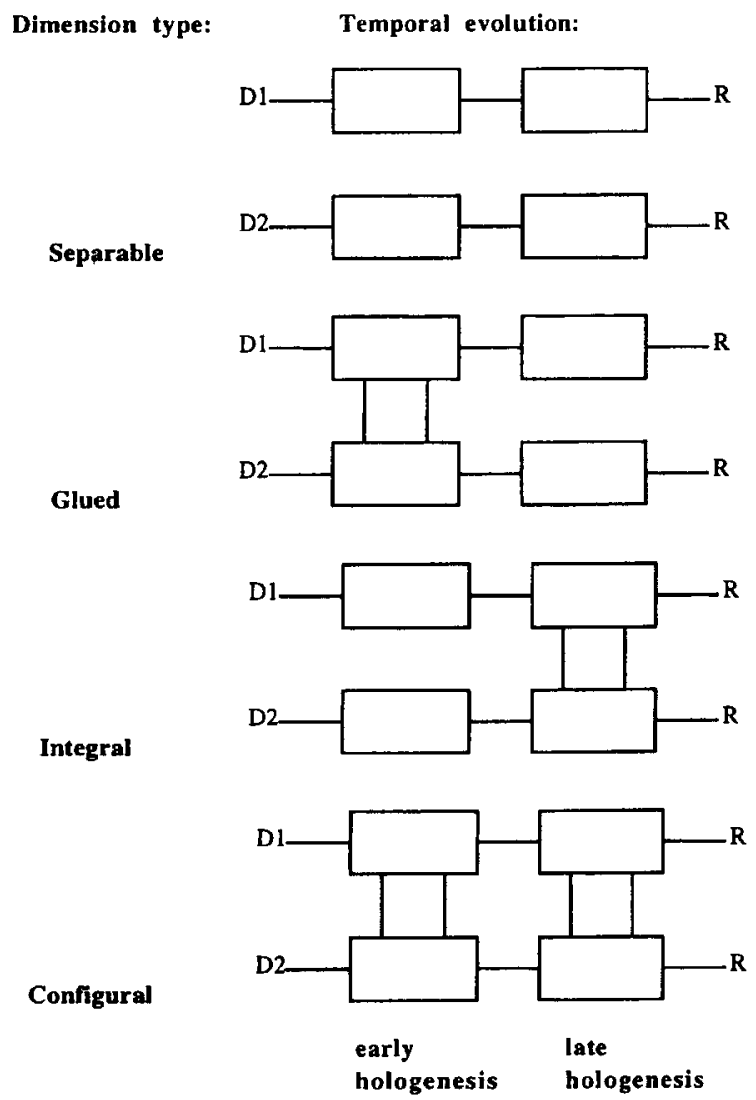

Figure 3. Four possible relations (separable, glued, integral, and configural) among dimensions, according to NET. Integration between dimensions is shown by vertical connecting lines.

will be encountered frequently. While this may be the reason why Pomerantz et al. failed to obtain Stroopwithout-Garner interference, NET, however, indicates that this may sometimes occur-for instance, with complex, multidimensional stimuli that are nevertheless good forms.

Figure 4 shows the complete set of stimuli used in both experiments. It can be described in terms of four stimulus dimensions - two outer and two inner contours which, independently of each other, can take on a square or a triangular form. If one of these contours is the target, there are three nontarget dimensions for Stroop measurement, all of which can, independently of each other, be either congruous or incongruous with the target. In addition, for Garner-interference measurement on each dimension, independently of the other dimensions, nontarget conditions can be blocked or randomly intermixed. In Experiment 1, the interaction of multiple dimensions in Stroop and Garner interference was studied. NET predicts Stroop-without-Garner interference for these stimuli. In Experiment 2, all trials were randomly intermixed, precluding Garner measurement on this dimension. Instead, presentation time was varied. A mask, however, followed the stimulus, with minimal latencies long enough to secure interruption rather than integra- 


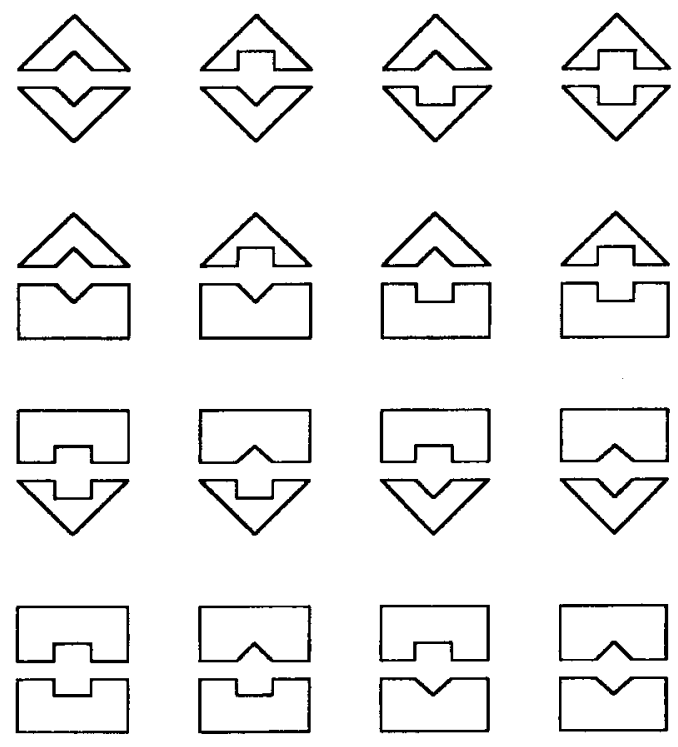

Figure 4. Stimuli used in both experiments.

tion masking. Hologenesis and the shift from integrative to nonintegrative strategy develop over time; assuming that a mask interrupts processing, it is possible to obtain a series of time slices through the course of this process, and thus to observe how Stroop interference varies as a function of presentation time.

\section{EXPERIMENT 1}

\section{Method}

\section{Subjects}

Twenty-two psychology students at the University of Amsterdam fulfilled course requirements by participating in the experiment. Eighteen of the subjects were female and 4 were male. Of the female subjects, 4 were left-handed; the remaining 14 female subjects, and all of the male subjects, were right-handed. All were required to perform a local and a global task; those who failed to complete a task were omitted from the analysis. Of the 4 subjects who did not complete the local task, 2 also failed to complete the global task, owing to apparatus problems.

\section{Stimuli}

The stimuli, shown in Figure 4, varied along the following four dimensions: upper global contour, upper local contour, lower global contour, and lower local contour. Each contour could have either a rectangular or a triangular shape as its feature, resulting in a total of $2 \times 2 \times 2 \times 2=16$ different stimuli. The size of the global contour of each stimulus was $1 \times 1.2 \mathrm{~cm}$, and the size of each local contour was $0.4 \times 0.6 \mathrm{~cm}$.

\section{Materials}

The subjects were seated in a sound-attenuated room, approximately $80 \mathrm{~cm}$ from the screen of a Macintosh Plus computer. The stimuli appeared on the screen, in the middle of a light rectangle measuring $9.3 \times 16.6 \mathrm{~cm}$ in a dark frame. The $k$ and the $d$ keys on the computer keyboard were used alternately as response keys between subjects. The $k$ key was green and the $d$ key was yellow.

\section{Procedure}

The subjects were instructed to classify the stimulus on one of four target dimensions as either a triangular or a rectangular shape.
The other dimensions were irrelevant. The subjects were encouraged to be as fast and as accurate as possible. A fixation point was initially presented for $50 \mathrm{msec}$ at the center of the blank screen, on the position that marked the middle of the stimulus that immediately followed. The stimulus remained on the screen until the subject responded by pressing a key. For each subject, reaction times (RTs) and number of correct responses were recorded. The screen remained clear for $1,000 \mathrm{msec}$ before the next trial started. The experiment was divided into four separate tasks, each having a different one of the four features as the target. Each task was preceded by a practice session, in which the subjects completed a total number of 16 practice trials. The number of correct responses in those 16 trials were displayed on the screen after the practice session, and no further feedback was given. The subjects completed two tasks, one with a global and one with a local target, in balanced order. Each task lasted about $1 \mathrm{~h}$ and the two tasks were completed on different days, a minimum of 3 days apart. Half of the subjects carried out the task with the upper targets, and the remainder carried out the task with the lower targets.

In each task, the nontargets were presented in both blocked and random order over trials in order to test Garner interference. In the blocked presentation, the nontarget feature was fixed, while in the random presentation, it was varied. Each of the three nontargets was presented in blocked or random order independently of the others in a $2 \times 2 \times 2$ factorial design. Each trial was repeated 10 times, resulting in a total of $16 \times 10 \times 2 \times 2 \times 2=1,280$ trials.

In each task, the trials were presented in 27 blocks, with the order of the blocks varying randomly between subjects. As a consequence of the Garner conditions, the blocks differed in terms of the number of stimuli presented within them. There were 8 blocks of 20 trials $(10 \times 2$ stimuli), 12 blocks of 40 trials $(10 \times 4$ stimuli), and 6 blocks of 80 trials $(10 \times 8$ stimuli), and there was 1 block of 160 trials $(10 \times 16$ stimuli).

\section{Results}

\section{Local Targets}

Analyses were performed separately for local and global targets. The subjects scored an average of $98 \%$ correct for local targets and $97 \%$ correct for global ones. A negative correlation was obtained between percent correct and RTs across conditions for the local task $(r=$ -.708 ), showing that faster responses were more accurate; no such correlation was obtained for the global task $(r=-.0056)$. There was thus no evidence of a speedaccuracy tradeoff, and percent correct was therefore discarded in further analyses. Analyses of variance (ANOVAs) were performed on the RTs, except those below $100 \mathrm{msec}$ or above $2,000 \mathrm{msec}$. Because there was no difference in overall outcome between targets in the upper half of the figure and those in the lower half, the results from both conditions were pooled. This yielded three nontarget types. For the local targets, these were: near global nontargets (i.e., the upper global nontargets for upper local targets and the lower global nontargets for lower local targets); distant global nontargets (i.e., the lower global nontargets for upper local targets and the upper global ones for lower local targets); and local nontargets (i.e., the lower local nontargets for upper local targets and the upper local ones for lower local targets). The nontargets were treated as factors in an ANOVA. Two factors belonged to each nontarget dimension - namely, one factor analyzing two levels of Stroop interference (congruous vs. incongruous), and one factor analyzing two levels of Gar- 
ner interference (blocked vs. random). This resulted in a six-factor $(2 \times 2 \times 2 \times 2 \times 2 \times 2)$ ANOVA. Significant effects will be discussed in the following sections.

Garner effects. The near global nontarget effect was significant $\left[F(1,17)=6.46, M S_{\mathrm{e}}=4,910.08, p<.05\right.$; in the blocked conditions, $M=485 \mathrm{msec}, S E=3.67$; in the random conditions, $M=495 \mathrm{msec}, S E=3.78]$. No other main effects were significant [for distant global nontargets, $F(1,17)=1.39, M S_{\mathrm{e}}=17,970.14$; for local nontargets, $\left.F(1,17)=2.38, M S_{\mathrm{e}}=24,245.12\right]$.

Stroop effects. A small $(8 \mathrm{msec})$ but significant Stroop effect was obtained on the local nontargets $[F(1,17)$ $=18.45, M S_{\mathrm{e}}=879.61, p<.0005$; for congruous nontargets, $M=486 \mathrm{msec}, S E=3.71$; for incongruous nontargets, $M=494 \mathrm{msec}, S E=3.75]$. For the near global nontargets, a significant Stroop effect was obtained $\left[F(1,17)=29.27, M S_{\mathrm{e}}=7,556.19, p<.0001\right.$; for congruous nontargets, $M=476 \mathrm{msec}, S E=3.50$; for incongruous nontargets, $M=504 \mathrm{msec}, S E=3.87$; Stroop effect $=28 \mathrm{msec}$ ).

For the distant global nontarget, too, a significant effect was obtained $\left[F(1,17)=49.74, M S_{\mathrm{e}}=1,162.28\right.$, $p<.0001]$. However, this effect was opposite that of Stroop interference: congruous distant global nontargets were slower than incongruous ones (congruous nontargets: $M=497 \mathrm{msec}, S E=3.88$; incongruous nontargets: $M=483 \mathrm{msec}, S E=3.56$; Stroop effect $=-14 \mathrm{msec}$ ). Given that Stroop effects are measures of attention, it seems natural to seek an explanation for the opposite effect in terms of attentional processes also.

Neither the Stroop interference for the local nontarget nor the opposite effect for distant global nontarget have a corresponding Garner effect. Thus, the effects cannot be reconciled with Pomerantz et al.'s (1989) model. However, these effects could be considered irregular, as the following discussion of the interactions suggests.

There were 3 two-factor interactions and 1 threefactor interaction involving only Stroop effects that were significant [for near global nontarget $\times$ local nontarget, $F(1,17)=24.90, M S_{\mathrm{e}}=2,051.95, p<.001$; for near global nontarget $\times$ distant global nontarget, $F(1,17)=$ $24.96, M S_{\mathrm{e}}=1,318.49, p<.0001$; for distant global nontarget $\times$ local nontarget, $F(1,17)=10.02, M S_{\mathrm{e}}=$ $2,139.34, p<.01$; and for near global nontarget $\times$ distant global nontarget $\times$ local nontarget, $F(1,17)=25.38$, $\left.M S_{\mathrm{e}}=702.92, p<.0001\right]$. As Table 1 shows, these interactions reveal an exception to the opposite-Stroopinterference effect, in that the fastest response times of all are obtained in the condition in which all nontargets are congruous with the target. When this condition is discarded, the opposite-Stroop effect is even larger for the distant global nontargets (Stroop effect $=-23.6$ ). Discarding this condition reduces the size of the Stroop effect for the near global nontarget (Stroop effect $=16.6$ ) and eliminates the effect for the local nontarget (Stroop effect $=-2$ ). This shows that the Stroop effect of the local nontarget is restricted to the all-congruent condition.

Both feature integration theory (Treisman \& Gelade, 1980 ) and NET could be applied to these observations,
Table 1

Stroop Interference for Local Targets: All-Same Effect (Experiment 1)

\begin{tabular}{|c|c|c|c|c|}
\hline \multicolumn{3}{|c|}{ Nontarget } & \multicolumn{2}{|c|}{$\begin{array}{l}\text { Reaction Time } \\
(\mathrm{msec})\end{array}$} \\
\hline Distant Global & Near Global & Local & $M$ & $S E$ \\
\hline con & con & $\operatorname{con}$ & 459 & 6.30 \\
\hline con & $\operatorname{con}$ & incon & 497 & 7.59 \\
\hline con & incon & con & 519 & 8.21 \\
\hline con & incon & incon & 514 & 7.89 \\
\hline incon & con & con & 472 & 6.82 \\
\hline incon & con & incon & 477 & 6.96 \\
\hline incon & incon & con & 494 & 7.32 \\
\hline incon & incon & incon & 488 & 7.29 \\
\hline
\end{tabular}

Note-con = congruous nontarget; incon $=$ incongruous nontarget.

since according to these views, form and location dimensions are initially processed separately, dimensions becoming integrated only later in order to find the location of a particular form. This integration need not be completed if all forms are the same, as all nontarget forms should produce the same answer. This suggests that the local Stroop effect is produced by an advantage due to early processing. On the other hand, a Stroop effect would never be obtained if it did not at least reveal the beginning of attentional processes, and therefore we may ascribe the effect for the local target in the allcongruent condition to early attentional binding, which we have termed "glued dimensions."

In extending feature integration theory, Treisman and Schmidt (1982) claimed that during the integration of the selected target features, the integration of to-beignored nontarget features is actively suppressed, in order to minimize the competition between target and nontargets (see also Tipper, 1985). Humphreys and Bruce (1989) explained this inhibition in terms of minimizing possible crosstalk during feature integration. Since crosstalk is held responsible for Garner interference, the result of this would be that there is no Garner interference corresponding to the condition in which the inhibition occurs. Tipper and Driver (1988) studied the processing of to-be-ignored pictures and words when attention was directed to a different picture or word. They demonstrated the inhibitory influence of the priming effect of an ignored picture on a subsequent categorically related picture, an influence they termed the negative priming effect. It could therefore be argued that, however anomalous it may seem, both of the effects that did not fit Pomerantz et al.'s (1989) account (namely, the ease of processing in the all-congruent condition and the inhibition of the distant global nontarget) may have as their basis one common underlying source - the early information-integration process during target selection.

Interaction of Stroop and Garner effects. If the view is correct that Stroop and opposite-Stroop effects are due to early attentional processes, interactions may be expected between these and Garner effects; if subjects can anticipate congruity or incongruity, as in the case of the blocked stimulus conditions, this will reduce the size 
of the Stroop (or opposite-Stroop) effect, and this in fact allows a prediction to be made on Stroop $\times$ Garner interaction. An opposite prediction could be derived on the basis of findings by Neill, Terry, and Valdes (1994), who recently showed that negative priming is also possible without selection. This view is in agreement with an episodic-retrieval theory of negative priming (Neill \& Valdes, 1992), according to which, the subject may remember that the nontarget was ignored, and this will interfere with their selection of the appropriate response. This is more likely to happen with blocked than with random nontargets, and this approach therefore makes an opposite prediction to that of feature integration theory and NET regarding the interaction between Stroop and Garner effects, in that the Stroop (or opposite-Stroop) effect will be increased rather than diminished in the blocked Garner conditions, in comparison with the random conditions.

Three second-order interactions between Stroop and Garner interference were obtained. The interaction between local Stroop and local Garner interference was marginally significant $\left[F(1,17)=3.17, M S_{\mathrm{e}}=961.78\right.$, $p<.1]$, whereas the interactions between near global Stroop and near global Garner and between distant global Stroop and distant global Garner were significant $\left[F(1,17)=11.74, M S_{\mathrm{e}}=2,118.3, p<.005\right.$, and $F(1,17)=$ $8.07, M S_{\mathrm{e}}=1,333.52, p<.05$, respectively]. Table 2 shows that for all of these nontargets, Stroop effects differ in size, depending on Garner conditions: they are stronger in the random than in the blocked Garner conditions. Another effect that yielded significance-namely, the interaction between local Stroop and near global Garner $\left[F(1,17)=4.80, M S_{\mathrm{e}}=640.16, p<.05\right]$-showed significant Stroop effects for local nontargets only when the near-global nontargets were blocked. These effects are in agreement with both Treisman's theory (Treisman \& Gelade, 1980) and NET, and argue against Neill and Valdes's (1992) episodic-retrieval theory of negative priming.

The following higher-order interactions were also significant: distant global Stroop $\times$ distant global Garner

Table 2

Interactions Between Stroop and Garner Interference, in Milliseconds (Experiment 1)

\begin{tabular}{|c|c|c|c|c|c|}
\hline \multirow[b]{3}{*}{ Nontargets } & \multicolumn{4}{|c|}{ Nontargets } & \multirow{3}{*}{$\begin{array}{c}\text { Stroop } \\
\text { Interference }\end{array}$} \\
\hline & \multicolumn{2}{|c|}{ Congruous } & \multicolumn{2}{|c|}{ Incongruous } & \\
\hline & $M$ & $S E$ & $M$ & $S E$ & \\
\hline \multicolumn{6}{|l|}{ Local } \\
\hline Blocked & 481 & 4.69 & 485 & 4.71 & 4 \\
\hline Random & 492 & 5.75 & 503 & 5.81 & 11 \\
\hline Garner interference & 11 & & 18 & & \\
\hline \multicolumn{6}{|l|}{ Near global } \\
\hline Blocked & 476 & 5.02 & 494 & 5.32 & 18 \\
\hline Random & 477 & 4.89 & 514 & 5.57 & 37 \\
\hline Garner interference & 0 & & 20 & & \\
\hline \multicolumn{6}{|l|}{ Distant global } \\
\hline Blocked & 489 & 5.02 & 481 & 4.80 & -8 \\
\hline Random & 505 & 5.89 & 484 & 5.27 & -19 \\
\hline Garner interference & 16 & & 3 & & \\
\hline
\end{tabular}

$\times$ local Garner $\left[F(1,17)=7.50, M S_{\mathrm{c}}=975.20, p<\right.$ $.05]$; distant global Stroop $\times$ near global Garner $\times$ distant global Garner $\left[F(1,17)=14.41, M S_{\mathrm{e}}=442.44, p<\right.$ $.005]$; near global Stroop $\times$ near global Garner $\times$ distant global Garner $\left[F(1,17)=7.62, M S_{\mathrm{e}}=3,042.65, p<\right.$ $.05]$; and distant global Stroop $\times$ local Stroop $\times$ distant global Garner $\times$ distant local Garner $[F(1,127)=5.66$, $\left.M S_{\mathrm{e}}=822.32, p<.05\right]$. There was also a marginally significant near global Stroop $\times$ near global Garner $\times$ distant global Garner $\times$ local Garner interaction $[F(1,17)=$ 3.64, $\left.M S_{\mathrm{e}}=823.30, p<.1\right]$.

Although the large number of conditions invites such interactions, these results may also suggest that Garner interference did occur in some conditions. As this would undermine the claim that Stroop, but not Garner, interference was obtained for distant global nontargets, we performed a post hoc analysis on these interactions, testing for a distant global Garner effect with a liberal level of $\alpha=.1$. To briefly summarize these findings, for 16 out of the remaining $2^{5}=32$ cells, there was a significant Garner effect on at least one of the 5 interactions (by our lean criterion, 36 times out of a possible $5 \times 32=$ 160 cells, a distant global Garner effect was significant. Except in four cases which could be considered spurious, these were all concentrated in random local nontarget conditions.

We may conclude that although a complete absence of Garner effects may not have been realized for the distant global nontargets, when these effects did occur, they were less robust than the corresponding Stroop-interference effects in two cases-that of the all-same condition, and that of the opposite-Stroop effect of the distant global nontarget. Such effects were not allowed for in Pomerantz et al.'s (1989) views. They can be explained, however, in terms of early attentional processes occurring during the attentional integration of the stimulus. Various interactions suggest that the predictability of the stimulus can reduce Stroop interference. The interactions between Stroop and Garner interference provide some support for the view that Stroop effects are early attentional, in terms of when they occur during perception.

\section{Global Targets}

A repeated measures six-factor ANOVA was performed on the RTs of 20 subjects, excluding those that were below $100 \mathrm{msec}$ or above $2,000 \mathrm{msec}$. RTs were on average faster for global targets than they were for local ones. This could be attributed to the greater visibility of the former-an issue which is not further pursued here. Because there were no differences in overall outcomes between targets in the upper half of the figure and those in the lower half, these conditions were pooled, yielding three nontarget types. For the global targets, these were near local nontargets (the upper local nontargets for upper global targets and the lower local ones for lower global targets), distant local nontargets (the lower local nontargets for upper global targets and the upper local ones for lower global targets), and global nontargets (the 
lower global nontargets for upper global targets and the upper global ones for lower global targets). Two factors belonged to each nontarget type-namely, a Stroop factor (congruous vs. incongruous) and a Garner factor (blocked vs. random), resulting in a six-factor $(2 \times 2 \times$ $2 \times 2 \times 2 \times 2$ ) ANOVA.

Garner interference. None of the three Garner factors reached significance [for near and distant local nontargets, $F<1$; for the global nontarget, $F(1,19)=2.14$, $M S_{\mathrm{e}}=5,356.43, p=.16$; for the blocked global nontarget, $M=402 \mathrm{msec}, S E=2.22$; and for the random nontarget, $M=408 \mathrm{msec}, S E=2.44]$ ]. A three-factor interaction between all three nontargets was obtained in the Garner-interference conditions $\left[F(1,19)=7.48, M S_{\mathrm{e}}=\right.$ $1,046.5, p<.05]$. Table 3 suggests that if either both local nontargets are random or both are blocked, no significant interference is obtained for the global nontarget. Garner interference may occur if one local nontarget is blocked and the other is random. These conditions may provide an extra source of difficulty for integration. Inconsistent blocking may give rise to higher-order incongruity, and conditions in which all nontargets are consistently either blocked or random may therefore be easier than those that are inconsistent. What is therefore nominally a Garner interference interaction--namely, an effect of incongruity between blocking on one dimension and randomness on the other-may well in fact be a higher-order Stroop effect.

Stroop effects. The Stroop effect was significant for near local nontargets $\left[F(1,19)=7.00, M S_{\mathrm{e}}=1,013.10\right.$, $p<.05$; for the congruous condition, $M=403 \mathrm{msec}$, $S E=2.33$, and for the incongruous one, $M=408 \mathrm{msec}$, $S E=2.34]$. It was not significant for distant local nontargets $(F<1)$, but was significant for global nontargets $\left[F(1,19)=7.69, M S_{\mathrm{e}}=1,133.37, p<.05\right.$; for congruous global nontargets, $M=408 \mathrm{msec}, S E=2.43$, and for incongruous global nontargets, $M=402 \mathrm{msec}, S E=$ 2.23 ]. In this case, incongruity facilitated the response with the global target. As with the local target, this result indicates opposite-Stroop interference. Stroop effects unmatched by Garner effects were thus obtained for near local and for global nontargets, contrary to predictions from Pomerantz et al.'s (1989) model. Moreover, the marginally significant Garner effect in the global nontarget condition was opposite to the Stroop effect.

Table 3

Garner Interference for Global Targets (Experiment 1)

\begin{tabular}{llllll}
\hline & Nontarget & & & \multicolumn{2}{c}{$\begin{array}{c}\text { Reaction Time } \\
\text { (msec) }\end{array}$} \\
\hline Global & Near Local & Distant Local & & $M$ & $S E$ \\
\hline Blocked & Blocked & Blocked & & 406 & 4.09 \\
Blocked & Blocked & Random & & 397 & 3.84 \\
Blocked & Random & Blocked & & 397 & 3.77 \\
Blocked & Random & Random & & 409 & 5.75 \\
Random & Blocked & Blocked & & 409 & 4.87 \\
Random & Blocked & Random & & 405 & 3.78 \\
Random & Random & Blocked & & 411 & 5.10 \\
Random & Random & Random & & 408 & 5.60 \\
\hline
\end{tabular}

The near local $\times$ global Stroop interaction was significant $\left[F(1,19)=11.46, M S_{\mathrm{e}}=695.36, p<.005\right.$; in the condition with congruous global nontargets and incongruous near local nontargets, $M=413 \mathrm{msec}, S E=$ 3.51 , whereas in the other three conditions, $M=402-$ $403 \mathrm{msec}, S E=3.07-3.34]$. This effect was also obtained, and interpreted as support for attentional theories, for the local targets.

Interactions between Stroop and Garner effects. The only other interaction that reached significance was the fivefold near local Stroop $\times$ global Stroop $\times$ near local Garner $\times$ distant local Garner $\times$ global Garner interaction $\left[F(1,19)=8.42, M S_{\mathrm{e}}=555.25, p<.01\right]$. This effect, which is hard to interpret, appears to be a combination of other inconsistency effects with the earliermentioned effect of inconsistent blocking between the local targets. It appears that whereas consistent blocking of the local targets suppresses any effects, including the global Garner effect, inconsistent local blocking makes the subjects aware of other inconsistencies; for instance, RTs reach their absolute peak for the blocked and random global Garner conditions $(M=411 \mathrm{msec}, S E=$ 8.93; $M=421 \mathrm{msec}, S E=12.89$, respectively), if the near local nontarget is random and the distant local nontarget is blocked, in the case of incongruous near local nontargets in combination with congruous global nontargets.

\section{Discussion}

\section{Local and Global Targets}

For the local targets, Stroop effects unmatched by Garner effects were found with the local nontarget in the all-same condition, and with the distant global nontargets. For the global targets, this occurred with the near local nontarget and with all global nontargets. In this respect, the results of Experiment 1 include a phenomenon-Stroop-without-Garner interference-that is not allowed for in Pomerantz et al.'s (1989) model (Figure 2), but that was, however, predicted by NET. We called this phenomenon "glued dimensions." It could be shown that the Stroop effects were reduced by predictability of the nontargets, which could be understood by assuming that less attention is devoted to predictable nontargets. This result supports an information-integration account of these phenomena (both Treisman's approach and NET fall into this category), and argues against one couched in terms of episodic retrieval (e.g., Neill \& Valdes, 1992). Experiment 1 therefore provides evidence for a model which understands Stroop and Garner interference in terms of flexible, attentional integration processes. Indirect evidence that glued dimensions are a result of early attentional processing was obtained from the interaction between Stroop and Garner interference, as well as from the all-congruent condition with the local targets; moreover, the fact that glued dimensions seem more frequent with global targets, for which RTs are shorter, is consistent with this assumption. Experiment 2 was conducted to provide a more direct test of this assumption. 
An opposite-Stroop effect for the distant global nontarget was obtained, with both local and global targets. In the preceding sections, it was suggested that these results could be caused by active suppression of integration. NET assumes that integration takes place across a gradually widening area, unless a strategic mechanism cuts it off or suppresses it. It is possible that the suppression is a result of the fact that the neglected information is part of a different figure. Kramer and Jacobson (1991) studied the influence of Gestalt grouping principles of similarity, closure, and proximity on the size of the response-compatibility effect in a focused-attention task. Their subjects responded to a centrally located target while attempting to ignore adjacent nontargets, which could be compatible, incompatible, or neutral with respect to the response required to the target. In addition, the nontargets and the targets could either be embedded in the same object or presented on different objects. Congruity effects were found when the target and nontarget were embedded in the same object. However, these effects were eliminated when the target and the nontarget were embedded in different objects, even when the distance between the items was less than $25^{\circ}$ of visual angle.

This suggests that object identity rather than location was the decisive criterion in terms of whether the subject was able to suppress integration or not. This raises the question of why, then, there is facilitation for the local nontarget in the local-target conditions, since the local nontarget is also part of another figure. In response, we would stress that this effect only reaches significance when circumstances optimally support integration-that is, when nontargets are most easily integrated (i.e., when they are all congruent) and when nontargets are predictable. On the other hand, however, this may lead us to have expected an opposite-Stroop effect also for the local nontarget. That this failed to occur may be due to the fact that the stimulus remained visible until a response was made. In Experiment 2, therefore, we used rapid, masked presentations of the stimuli to investigate how Stroop effects develop as a function of presentation times.

\section{EXPERIMENT 2}

\section{Method}

\section{Subjects}

Fifteen psychology students, none of whom had taken part in Experiment 1, participated in Experiment 2. Twelve of the subjects were female and 3 were male. Apart from one of the female subjects, all were right-handed. One subject who failed to complete the global task was omitted from the analysis for that task.

\footnotetext{
Stimuli and Materials

The stimuli and materials were the same as those used in Experiment 1.

\section{Procedure}

The same Stroop conditions were used as in Experiment 1, but trials were only presented in random order; the blocked presentations of Experiment 1 were omitted. Stimulus presentation time
}

was varied; 66.6-, 83.3-, 100-, 116.6-, 133.3-, 150-, 166.6-, and 183.3-msec presentations were used, all being multiples of 16.67 , the refresh rate of the screen. Presentation times were chosen that were longer than $60 \mathrm{msec}$ (in order to obtain a flat curve of percentcorrect identifications as a function of presentation time [Glezer \& Newskaja, 1963; Glezer \& Zukkerman, 1961, both cited in Klix, 1978, pp. 275-276]) but less than $200 \mathrm{msec}$ (the average duration of a fixation). A mask immediately followed the stimulus. This mask was a light-gray dot pattern that remained on the screen until the subjects pressed one of the response buttons. All 128 conditions ( 16 stimuli $\times 8$ presentation times) were repeated 9 times; the subjects thus completed $9 \times 128=1,152$ trials, in random order. The experiment, which included eight breaks, lasted about $1 \mathrm{~h}$.

\section{Results and Discussion}

The subjects scored an average of $96 \%$ correct in the local task and $95 \%$ correct in the global task. Correct identification did not depend on presentation time, in agreement with the results that had earlier been obtained for similarly complex stimuli presented for $60 \mathrm{msec}$ or longer (Glezer \& Newskaja, 1963; Glezer \& Zukkerman, 1961, both cited in Klix, 1978, pp. 275-276). There was a negative correlation between RT and percent correct $(-.48$ and -.26 for local and global targets, respectively). Since there was, therefore, no evidence of any speed-accuracy tradeoff, percent correct was omitted from further analysis. ANOVAs were performed on the RTs, after those below $100 \mathrm{msec}$ and above $2,000 \mathrm{msec}$ had been excluded.

\section{Local Targets}

As in Experiment 1, "local target" in the following analyses includes the data of both local targets-that in the upper half and that in the lower half of the figurethat were pooled to obtain one local target. A repeated measures four-factor ANOVA was performed, with three Stroop factors (near global nontarget [congruous vs. incongruous with the target], distant global nontarget [congruous vs. incongruous], and local nontarget [congruous vs. incongruous]), together with a fourth factor of presentation time (of which there were eight). The effects involving presentation times will be discussed later, in conjunction with those of the global targets.

The effect of local nontargets was marginally significant $\left[F(1,14)=3.42, M S_{\mathrm{e}}=1,215.67, p<.1\right.$; subjects responded faster to congruous local nontargets $(M=$ $616 \mathrm{msec}, S E=3.09$ ) than they did to incongruous ones $(M=620 \mathrm{msec}, S E=3.36)]$. The effect of the near global nontargets was significant $[F(1,14)=21.84$, $M S_{\mathrm{e}}=1,879.96, p<.0004 ;$ subjects responded faster to congruous near global nontargets $(M=612 \mathrm{msec}, S E=$ 3.22) than to incongruous ones $(M=625 \mathrm{msec}, S E=$ 3.21)]. The effect of the distant global nontargets was also significant $\left[F(1,14)=8.05, M S_{\mathrm{e}}=1,735.22, p<\right.$ .05 ; subjects responded faster to incongruous distant global nontargets $(M=614 \mathrm{msec}, S E=3.09)$ than they did to congruous ones $(M=622 \mathrm{msec}, S E=3.35)]$. The near global nontarget $\times$ local nontarget interaction was significant $\left[F(1,14)=7.52, M S_{\mathrm{e}}=729.44, p<.05\right]$; while that between distant global nontarget $\times$ local 
Table 4

Stroop Interference for Local Targets: All-Same Effect (Experiment 2)

\begin{tabular}{|c|c|c|c|c|}
\hline \multicolumn{3}{|c|}{ Nontarget } & \multicolumn{2}{|c|}{$\begin{array}{l}\text { Reaction Time } \\
(\mathrm{msec})\end{array}$} \\
\hline Distant Global & Near Global & Local & $M$ & $S E$ \\
\hline con & con & con & 603 & 6.44 \\
\hline con & $\operatorname{con}$ & incon & 622 & 7.00 \\
\hline con & incon & con & 632 & 6.25 \\
\hline con & incon & incon & 631 & 6.80 \\
\hline incon & con & con & 611 & 5.87 \\
\hline incon & con & incon & 610 & 6.34 \\
\hline incon & incon & con & 618 & 5.90 \\
\hline incon & incon & incon & 618 & 6.64 \\
\hline
\end{tabular}

Note - con $=$ congruous nontarget; incon $=$ incongruous nontarget.

nontarget was marginally so $\left[F(1,14)=4.50, M S_{\mathrm{e}}=\right.$ $1,407.35, p<.1]$. The threefold local $\times$ near global $\times$ distant global nontarget interaction was significant $\left[F(1,14)=6.05, M S_{\mathrm{e}}=1,081.17, p<.05\right]$. As Table 4 shows, these interactions duplicate the all-same effect of Experiment 1 . This effect, ascribed to attentional target selection, appears to be robust across presentation times. The same applies to the main effects and interactions, which show similar Stroop effects for the local targets as in Experiment 1.

\section{Global Targets}

The data of both global targets - that in the upper half and that in the lower half of the figure-were pooled. A repeated measures four-factor ANOVA was performed on 14 subjects, with three Stroop factors (near local nontarget [congruous vs. incongruous with the target], distant local nontarget [congruous vs. incongruous], and global nontarget [congruous vs. incongruous]), and a fourth factor of presentation time (of which there were eight). No main effects reached significance for the global targets $(F<1)$, but a three-factor near local $\times$ distant local $\times$ global nontarget interaction was significant $\left[F(7,84)=7.98, M S_{\mathrm{e}}=1,603.090, p<.05\right]$. This result is similar to that of Experiment 1.

\section{Presentation-Time Effects}

For the local targets, the effect of presentation times was significant $[F(7,98)=116.63, M S e=1,609.31$, $p<.0001]$. Averaged over local and global targets, RTs increased with presentation times, as follows: 538,603 , $593,600,593,593,668,672 \mathrm{msec}$. That RTs increase with presentation time might seem counterintuitive, yet it could well be explained as an effect of hologenesis and strategy shift. For the shortest presentation time $(66.6 \mathrm{msec})$, no dimensional integration, and hence the least amount of interference, is expected. From then on, with increasing presentation time $(83.3-150 \mathrm{msec})$, RTs are constant, and this may be the stage at which integration takes place, resulting in interference. There is then, for the longest two presentation times $(166.6-183.3 \mathrm{msec})$, a further step increase in RTs. This is the stage at which the strategy shifts to a nonintegrative one. Such a large- scale change could lead to an overall destabilization of the system, which may explain the longer RTs at this stage.

For the local targets, presentation time interacted significantly with local and distant global nontargets $\left[F(7,98)=3.99, M S_{\mathrm{e}}=1,160.28, p<.001 ; F(7,98)=\right.$ $\left.2.77, M S_{\mathrm{e}}=1,282.36, p<.05\right]$. The interaction between presentation time and near global nontargets was not significant $\left[F(7,98)=1.53, M S_{\mathrm{e}}=1,303.29\right]$. Figure 5 shows the difference (incongruous minus congruous nontarget in msec) for the local targets (as well as the global ones). A positive score indicates Stroop interference, while a negative score indicates the opposite effect (i.e., opposite-Stroop interference). For the local targets, with the near global nontargets, the effect reaches a positive peak, of $30 \mathrm{msec}$, at $133.3-\mathrm{msec}$ presentation time (for other presentation times, the effect ranges from 5-15 msec). For the local nontargets, the effect reaches a negative peak value (of approx. $-13 \mathrm{msec}$ ) at 133.3msec presentation time, and a positive one (of approx. $29 \mathrm{msec}$ ) at 166.6 -msec presentation time, with nearzero effects otherwise. For the distant global nontargets, there is a negative peak (of approx. $-25 \mathrm{msec}$ ) at 133msec presentation time, with effects otherwise oscillating around zero $(p<.05)$.

For the global targets, likewise, RTs increased significantly with presentation time; a minimum RT $(M=$ $528 \mathrm{msec}$ ) was obtained at $66.6-\mathrm{msec}$ presentation time and a maximum RT $[M=683 \mathrm{msec} ; F(7,84)=111.89$, $\left.M S_{\mathrm{e}}=2,177.40, p<.0001\right]$ was reached at $183.3-\mathrm{msec}$ presentation time. A two-factor presentation time $\times$ global nontarget interaction was significant $[F(7,84)=$ $\left.2.67, M S_{\mathrm{e}}=1,531.08, p<.05\right]$, as was a three-factor presentation time $\times$ near local $\times$ distant local nontarget interaction $\left[F(7,84)=2.69, M S_{\mathrm{e}}=1,605.187, p<.05\right]$ and a four-factor presentation time $\times$ near local $\times$ distant local $\times$ global nontarget interaction $[F(7,84)=$ $\left.2.48, M S_{\mathrm{e}}=1,508.384, p<.05\right]$.

Figure 5 shows three sets of Stroop-interference curves, each set consisting of pairs of nontargets with similar distances from the target. Nearest nontargets, which were embedded in the same figure as the targets, show a positive peak in Stroop interference at $133.3 \mathrm{msec}$, suggesting that this might be the moment at which hologenesis reached the nearest nontarget, to integrate it with the target. For longer presentation times, the Stroop effect is reduced, which may indicate that the strategy shifted from an integrative to a nonintegrative one as presentation time increased. Intermediate nontargets were the next nearest ones to the target; they were presented on the figure opposite the one on which the target was located. At the same presentation time at which the nearest nontargets became integrated (i.e., $133 \mathrm{msec}$ ), these nontargets show a negative peak signaling oppositeStroop interference, indicating suppression of this irrelevant information during the time that the figure on which the target was located was integrated. This suppression probably has the function of minimizing spurious integration from the other component figure, since integration of information that is close to, but not part of, 


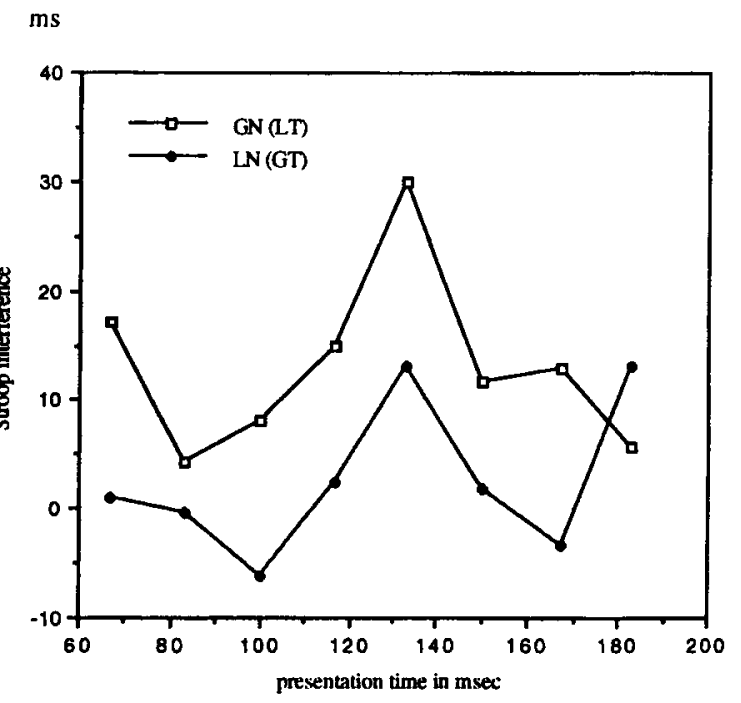

Nearest Nontargets

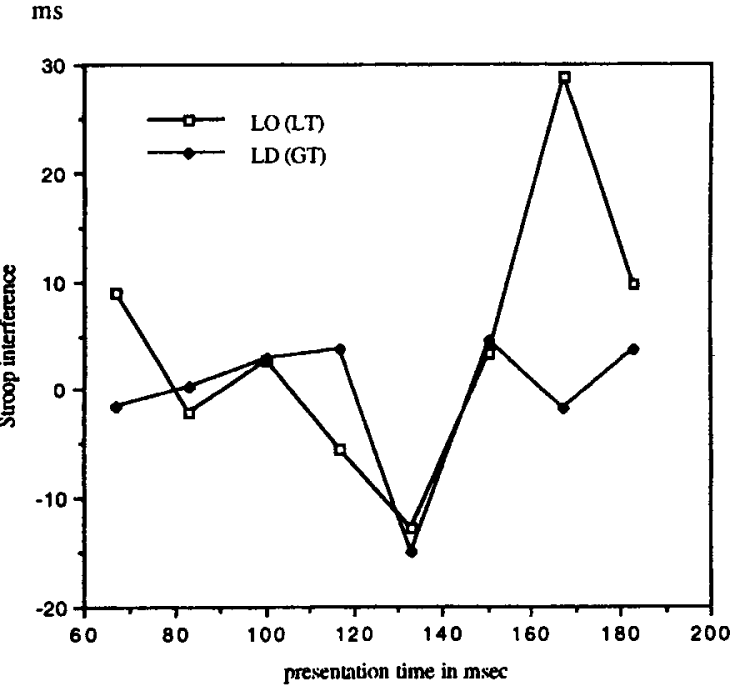

Intermediate Nontargets

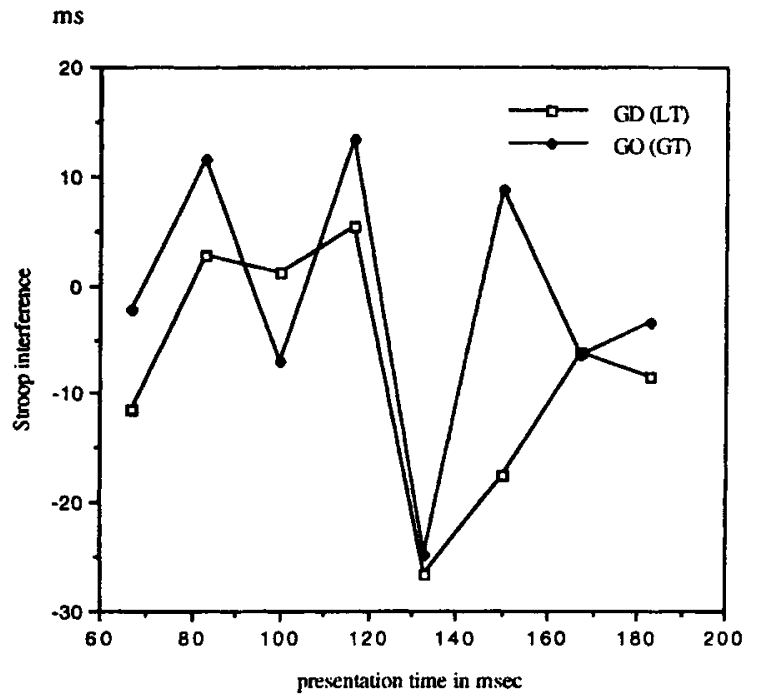

Most Distant Nontargets

Figure 5. Stroop and opposite-Stroop effects as a function of presentation time. Nearest nontargets: GN(LT) = near global nontarget, with local target; LN(GT) = near local nontarget with global target. Intermediate nontargets: LO(LT) = local nontarget with local target; (LD)GT = distant local nontarget with global target. Most distant nontargets: GD(LT) = distant global nontarget with local target; GO(GT) $=$ global nontarget with global target.

the figure containing the target is temporarily suspended (cf. Tipper \& Driver, 1988).

Immediately after the negative peak, a positive one occurs at $166 \mathrm{msec}$ for one of the intermediate nontargets. Of these two nontargets, this is the one that was closest to the target, though it, too, was situated on the other figure. Whereas Kramer and Jacobson's (1991) assumptions could explain the negative peak at $133 \mathrm{msec}$, separate ones would have been needed to explain this positive peak that suggests that attention seems gradually to expand as a function of presentation time. A ring model of spatial attention (Egly \& Homa, 1984; Juola, Bouwhuis, Cooper, \& Warner, 1991) seems more in agreement with this result than a zoom-lens model (Eriksen \& St. James, 1986; LaBerge, 1983), because the latter would have predicted a positive peak at $166 \mathrm{msec}$ for the nearest nontargets as well. Regardless of which model of attention is preferred, the effect of the expansion is that once the integration of the figure has been completed, attention is stretched beyond the figure that contains the target to integrate more components of the stimulus into the overall structure. The expansion is therefore in agreement with hologenesis.

For the longer presentation times, the shift to a nonintegrative strategy was assumed to interrupt further integration. In support of this assumption, the negative peak 
is not followed by a positive peak for the more distant of the two intermediate nontargets, and neither is there a positive peak in the curves for the distant nontargets. These curves do show more variance for these nontargets than for the previous ones, which is a general observation for later items in a sequential process.

Assuming that the mask interrupts processing, these results can be explained in terms of hologenesis and coherence length, whereby beyond $166 \mathrm{msec}$, a shift in strategy from an early integrative to a late nonintegrative one occurs, with the result that hologenesis is interrupted and all interference curves fall.

\section{GENERAL DISCUSSION}

Experiment 1 provided four instances of Stroopwithout-Garner interference. Local and distant global nontarget information appeared "glued" to the local targets, and near local and global nontarget to the global targets, early in perception. This was held to be impossible according to the model of Pomerantz et al. (1989), but was explained by NET as a combined effect of automatic hologenesis and a strategic shift from an integrative to a nonintegrative processing mode. The effects obtained have not previously been reported in the literature, and it is not likely that the Stroop-without-Garner interference will generalize under laboratory conditions to a large range of different stimuli. However, generalizability in this case is not an appropriate criterion with which to assess the data, since it was predicted that these effects would be rare.

We have explained in detail the atypicality of the effects for local targets, as well as some of the interactions suggesting that Garner effects did occur, albeit in a restricted number of conditions. At least we could conclude that for this set of stimuli, Garner interference was less, rather than more, robust than Stroop interference. Moreover, the Stroop effects of Experiment 1, in which viewing time was unrestricted, were replicated with short viewing times in Experiment 2.

By referring to the conditions in which Stroopwithout-Garner occurs as "perceptual glue," we are not implying that binding of features is solely due to an automatic process. A vertical-process decomposition was assumed to occur in perception, whereby attentional processes interact with automatic processes from the onset. In this way, attentional processes, which are at a higher level, exert an aspecific influence on the smallerscale, automatic information-integration processes of hologenesis.

In Experiment 2, the interplay of these automatic and strategic components could be seen to be a function of time in the Stroop-interference curves. They were observed by interrupting perceptual processing after a variable, short presentation time (presentation times were chosen that were long enough, however, to obtain the necessary information from the stimulus, as percent correct was invariably high in all presentation times). At the start of hologenesis, target and nontarget information are separate. The integrative character of the strategy is such that at $133-\mathrm{msec}$ presentation time, the target can be seen to become integrated with the nearest nontarget (shown by a peak in interference effect), at the same time suppressing the integration (shown by a negative peak in interference effect) for the next-nearest nontargets. At $166 \mathrm{msec}$, the largest of these nontargets is integrated; beyond that time, there is no further sign of integration, as all Stroop interference is suppressed after $166 \mathrm{msec}$ by the shift to a nonintegrative strategy. In sum, whereas the outward expanding of integration could be understood in terms of hologenesis, the suppression of all interference effects for presentation times longer than $166 \mathrm{msec}$ shows the effect of a shift to a nonintegrative strategy.

We may conclude that the results of both experiments support NET as an approach to Stroop and Garner interference. NET has the advantage of being an interactive, rather than a feedforward, perceptual organization theory (see Melara \& Marks, 1990), accounting for interference in terms of the interplay of automatic and strategic components (see Melara, 1989).

Although both the assumption of hologenesis and that of strategy shift were needed to predict the occurrence of glued dimensions, the empirical foundations of these notions do not rest on the present experiments alone. Hologenesis has been extensively reported (see van Leeuwen, 1995, for an overview). The problem is that, on the basis of Navon's (1977) studies, some authors have believed that a gestalt could also develop from global to local. Thus, both hologenesis (from local to global) and merogenesis (from global to local) seemed to occur, and there therefore seemed to be no underlying principle involved as to which comes first. This confusion is of long standing (Sander, 1930), and still seems to persist today (e.g., Hanlon, 1991). In our view, it rests on a confounding of the question of what the functional difference between local and global is (i.e., the difference between higher and lower orders of information, or between individual features and emergent properties) with the question of what the spatial difference between them is (i.e., the difference between small vs. big, or high vs. low spatial frequencies). In our view, hologenetic processes that are of the functional kind depend essentially on recurrent connections giving rise to oscillatory processes within the neural network. These are to be found from the primary visual cortex onward. The asymmetries between spatially local and spatially global processes may depend on the relative speed and sensitivity of afferent channels tuned to specific spatial frequencies. Hughes, Fendrich, and Reuter-Lorenz (1990) showed that in the absence of low spatial frequencies, the Navon effect is suppressed, suggesting that it is due to these spatial-frequency-tuned channels. Once it is realized, however, that the work of Navon, important as it may be in its own right, has little direct significance for issues of gestalt formation (see Kimchi, 1992), an underlying question remains to be answered, concerning hologenesis as far as the mandatory component is concerned. 
Whereas the hologenetic process runs from local to global, strategies can move in either direction-from local (nonintegrative) to global (integrative), or vice versa. An integrative strategy (in this sense, meaning a global precedence) was first found in the present experiments. Evidence for the assumption that strategy has only a nonspecific influence on the process, and that it varies on an integrative/nonintegrative dimension, has previously been reported (Stins \& van Leeuwen, 1993).

In fact, therefore, the only assumption newly made for these experiments concerns the notion of strategy shift during the hologenetic process. Rather than a shift from integrative to nonintegrative, a shift in the reverse direction might seem more likely, as this would recapitulate the microgenetic process on a higher level. Such a shift would pick up local features context free early during hologenesis, and would perceive the global gestalt arising later in a broad context. This would be optimal for picking up structural invariants during all stages of the microgenetic process. If a pattern has to be learned, this is what we may expect to occur, and in this way, we may explain that in learning and development situations, a shift from a nonintegrative to an integrative strategy seems to occur (Elman, 1993; van Leeuwen et al., 1988; van Leeuwen, Smitsman, \& van Leeuwen, 1994). Elman (1993) comes close to our coherence-length assumption. In his view, at an early stage during learning, small-scale regularities must be learned prior to higher-order ones. Without knowledge of what the proper chunks are, the system will drown in the spurious higher-order regularities. In our view, there is an additional reason why a shift from a nonintegrative to an integrative strategy will be most frequently encountered: it recapitulates hologenesis on the strategic level. Separate processing early in hologenesis goes together well with a nonintegrative strategy, and an integrative strategy will allow the system to benefit optimally from the global integration reached in the later stage of hologenesis.

In our stimuli, we provoked a strategy shift in the opposite direction, only to obtain Stroop-without-Garner interference. We did so by presenting stimuli in which a detail of a complex, multidimensional regular figure had to be reported. We readily admit that this sequence of strategies may be an oddity in the laboratory, and, indeed, this may be a reason why Pomerantz et al. (1989) and others failed to obtain it (but see LaGasse, 1993). For such reasons, some might call its theoretical significance doubtful. On the other hand, one sometimes has to provoke an odd situation in order to test a popular, widely accepted model.

Moreover, what may be an oddity in the laboratory need not be so rare in more natural situations, where it is probably not as unusual as it is in the laboratory to be surrounded by multiple irrelevant stimulus properties, strongly bound together by overall figure goodness. If a target has to be selected under these circumstances, we could be very satisfied with a perceptual system that, despite the difficulty of assembling a whole from its components, is able to obtain an impression from the whole, followed by context-free selection, within, say, $200 \mathrm{msec}$, the average duration of a fixation. The present study seems to suggest that, in this respect, the human perceptual system leaves us with little to complain about.

\section{REFERENCES}

Biederman, I. (1987). Recognition by components: A theory of human image understanding. Psychological Review, 94, 115-147.

DE Groot, A. M. B. (1984). Primed lexical decision: Combined effects of the proportion of related prime-target pairs and the stimulus-onset asynchrony of prime and target. Quarterly Journal of Experimental Psychology, 36A, 253-280.

DE GROOT, A. M. B. (1985). Word-context effects in word naming and lexical decision. Quarterly Journal of Experimental Psychology, 37A, 281-297.

EgLY, R., \& Homa, D. (1984). Sensitization of the visual field. Journal of Experimental Psychology: Human Perception \& Performance, 10, 778-793.

Elman, J. L. (1993). Learning and development in neural networks: The importance of starting small. Cognition, 48, 71-99.

ERIKSEN, B. A., \& ERIKSEN, C. W. (1974). Effects of noise letters upon the identification of a target letter in a nonsearch task. Perception \& Psychophysics, 16, 143-149.

ERIKSEN, C. W., \& ST. JAMES, J. D. (1986). Visual attention within and around the field of focal attention: A zoom lens model. Perception \& Psychophysics, 40, 225-240.

Flowers, J. H. (1990). Priming effects in perceptual classification. Perception \& Psychophysics, 47, 135-148.

GARNER, W. R. (1970). The stimulus in information processing. American Psychologist, 25, 350-358.

GARNER, W. R. (1988). Facilitation and interference with a separable redundant dimension in stimulus comparison. Perception \& Psychophysics, 44, 321-330.

GeIsSLER, H.-G. (1991). Zeitcodekonstanten--ein Bindeglied zwischen Psychologie und Physiologie bei der Erforschung kognitiver Prozesse? Hypothesen und Überlegungen zu Quantenstrukturen in der Alpha-Aktivität des Gehirns. Zeitschrift für Psychologie, 199, 121-143.

HANLON, R. E. (1991). Introduction. In R. E. Hanlon (Ed.), Cognitive microgenesis. A neuropsychological perspective (pp xi-xix). Berlin: Springer Verlag.

Hogeboom, M.; \& VAN Leeuwen, C. (1995). Complexity effects in local and global visual search strategies. Manuscript submitted for publication.

HOLENDER, D. (1992). Expectancy effects, congruity effects, and the interpretation of response latency measurement. In J. Alegria, D. Holender, J. Junça de Morais, \& M. Radeau (Eds.), Analytic approaches to human cognition (pp. 351-375). Amsterdam: Elsevier

Hughes, H. C., Fendrich, R., \& Reuter-LoRENZ, P. A. (1990). Global versus local processing in the absence of low spatial frequencies. Journal of Cognitive Neuroscience, 2, 272-282.

Humphreys, G. W., \& Bruce, V. (1989), Visual cognition: Computational, experimental and neuropsychological perspectives. London: Erlbaum.

Juola, J. F., Bouwhuis, D. G., Cooper, E. E., \& Warner, C. B (1991). Control of attention around the fovea. Journal of Experimental Psychology: Human Perception \& Performance, 17, $125-$ 141.

KIMcHI, R. (1992). Primacy of wholistic processing and global/local paradigm: A critical review. Psychological Bulletin, 112, 24-38.

KLIX, F. (1978). Information und Verhalten [Information and Behavior]. Berlin: Verlag der Wissenschaften.

Kramer, A. F., \& JaCOBSON, A. (1991). Perceptual organization and focused attention: The role of objects and proximity in visual processing. Perception \& Psychophysics, 50, 267-284.

LABERGE, D. (1983). Spatial extent of attention to letters and words Journal of Experimental Psychology: Human Perception \& Performance, 9, 371-379.

LAGASSE, L. L. (1993). Effects of good form and spatial frequency on global precedence. Perception \& Psychophysics, 53, 89-105. 
LEBEDEv, A. N. (1990). Cyclical neural codes of human memory and some quantitative regularities in experimental psychology. In H.-G. Geissler (Ed.), Psychophysical explorations of mental structures (pp. 304-310). Lewiston, NY: Hogrefe \& Huber.

MACLEOD, C. M. (1991). Half a century of research on the Stroop effect: An integrative review. Psychological Bulletin, 109, 163-203.

Melara, R. D. (1989). Dimensional interaction between color and pitch. Journal of Experimental Psychology: Human Perception \& Performance, 15, 69-79.

Melara, R. D., \& Marks, L. E. (1990). Dimensional interactions in language processing: Investigating directions and levels of crosstalk. Journal of Experimental Psychology: Learning, Memory, \& Cognition, 16, 539-554.

NAvon, D. (1977). Forests before trees: The precedence of global features in visual perception. Cognitive Psychology, 9, 353-383.

Neill, W. T., Terry, K. M., \& VAldes, L. A. (1994). Negative priming without probe selection. Psychonomic Bulletin \& Review, 1, 119-121.

NeILl, W. T., \& VALdES, L. A. (1992). Persistence of negative priming: Steady state or decay? Journal of Experimental Psychology: Learning, Memory, \& Cognition, 18, 565-576.

Paquet, L. (1994). Does the attentional state determine processing dominance in to-be-ignored compound stimuli? Acta Psychologica, 85, 155-169.

PatteE, H. H. (1973). The physical basis and origin of hierarchical control. In H. H. Pattee (Ed.), Hierarchy theory: The challenge of complex systems (pp. 71-108). New York: Braziller.

Pomerantz, J. R., \& GARNER, W. R. (1973). Stimulus configuration in selective attention tasks. Perception \& Psychophysics, 14, 565-569.

Pomerantz, J. R., \& Pristach, E. A. (1989). Emergent features, attention and perceptual glue in visual form perception. Journal of Experimental Psychology: Human Perception \& Performance, 15, 635649.

Pomerantz, J. R., Pristach, E. A., \& Carson, C. E. (1989). Attention and object perception. In B. Shepp \& S. Ballesteros (Eds.), Object perception: Structure and process (pp. 53-89). Hillsdale, NJ: Erlbaum.

Pomerantz, J. R., \& SAGER, L. C. (1975). Asymmetric integrality with dimensions of visual pattern. Perception \& Psychophysics, 18, 460466.

SANDER, F. (1930). Structures, totality of experience, and gestalt. In C. Murchison (Ed.), Psychologies of 1930 (pp. 191-270). Worcester, MA: Clark University Press.

Sekuler, A. B., \& Palmer, S. E. (1992). Perception of partly occluded objects: A microgenetic analysis. Journal of Experimental Psychology: General, 121, 95-111.

Stins, J., \& van Leeuwen, C. (1993). Context influence on the perception of figures as conditional upon perceptual organization strategies. Perception \& Psychophysics, 53, 34-42.
STroop, J. R. (1935). Studies of interference in serial verbal reactions. Journal of Experimental Psychology, 18, 643-662.

SWINNEY, D. A. (1979). Lexical access during sentence comprehension: (Re)consideration of context effects. Journal of Verbal Learning \& Verbal Behavior, 18, 645-659.

TIPPER, S. P. (1985). The negative priming effect: Inhibitory priming by ignored objects. Quarterly Journal of Experimental Psychology, 37A, 571-590.

Tipper, S: P., \& Driver, J. (1988). Negative priming between pictures and words in a selective attention task: Evidence for semantic processing of ignored stimuli. Memory \& Cognition, 16, 64-70.

Treisman, A. M., \& Gelade, G. (1980). A feature integration theory of attention. Cognitive Psychology, 12, 97-136.

Treisman, A., \& SchmidT, H. (1982). Illusory conjunctions in the perception of objects. Cognitive Psychology, 14, 107-141.

TURVEY, M. T. (1973). On peripheral and central processes in vision: Inferences from an information processing analysis of masking with patterned stimuli. Psychological Review, 80, 1-52.

VAN LEEUWEN, $C$. (in press). Task, intention, context, globality, ambiguity: More of the same. In M. Stadler \& P. Kruse (Eds.), Perceptual multistability and semantic ambiguity. Berlin: Springer Verlag.

van Leeuwen, C., Buffart, H., \& van Der Vegt, J. (1988). Sequence influence on the organization of meaningless serial stimuli: Economy after all. Journal of Experimental Psychology: Human Perception \& Performance, 14, 481-502.

van Leeuwen, C., Hogeboom, M., \& Bakker, L. (1995). Stimulus, representation and process aspects of figural goodness. Manuscript submitted for publication.

van Leeuwen, C., Hogeboom, M., \& Rouw, R. (1995). Hysteresis and enhanced contrast in perceptual classification: The role of strategic variables. Manuscript submitted for publication.

van Leeuwen, C., \& Steijvers, M. (1994). Use of synchronized chaotic oscillations to model multistability in perceptual grouping. Unpublished manuscript.

van Leeuwen, C., Weitenberg, N., \& Smit, D. (1995). Context influences on the perception of the Necker cube. Manuscript submitted for publication.

van Leeuwen, L., Smitsman, A., \& van Leeuwen, C. (1994). Tooluse in infancy: Perception of a higher-order relationship. Journal of Experimental Psychology: Human Perception \& Performance, 20, $1-18$.

von der Malsburg, C., \& Schneider, W. (1986). A neural cocktailparty processor. Biological Cybernetics, 54, 29-40.

(Manuscript received November 3, 1993; revision accepted for publication October 18, 1994.) 